\title{
Phellinins $A 1$ and $A 2$, new styrylpyrones from the culture broth of Phellinus sp. KACC93057P: II. Physicochemical properties and structure elucidation
}

\author{
In-Kyoung Lee ${ }^{1}$, Jin-Young Jung ${ }^{1}$, Young-Ho Kim ${ }^{2}$ and Bong-Sik Yun ${ }^{1}$ \\ The Journal of Antibiotics (2009) 62, 635-637; doi:10.1038/ja.2009.83; published online 28 August 2009
}

Keywords: biosynthesis; chemical structure; phellinins A1 and A2; Phellinus sp. KACC93057P

In a continuous search for novel styrylpyrones from the culture broths of Phellinus isolates using HPLC analysis and free radical scavenging activity, we found that Phellinus sp. KACC93057P produced new styrylpyrones, phellinins A1 and A2 (Figure 1), together with the known compounds, hispidin and 1,1-distyrylpyrylethan. Phellinin A (1) was identified as a mixture of isomers (A1 and A2) with the same ratio by NMR experiments. These compounds were structurally related to siccanochromene A and cyclorenierins, ${ }^{1,2}$ which are terpenes from the fungus Helminthosporium siccans and the sponge Haliclona sp., respectively. The identification and fermentation of the producing microorganism Phellinus sp. KACC93057P, in addition to the isolation and antioxidant activity of $\mathbf{1}$, were described in an earlier paper. ${ }^{3}$ This report describes the physicochemical properties and structure determination of 1 using spectroscopic methods including NMR and mass spectrometry.

The physicochemical properties of $\mathbf{1}$ are summarized in Table 1 . Compound $\mathbf{1}$ was isolated as an orange powder. It was readily soluble in dimethyl sulfoxide and methanol, poorly soluble in $\mathrm{CHCl}_{3}$ and water, and insoluble in hexane. Compound $\mathbf{1}$ had UV absorption maxima at 257 and $391 \mathrm{~nm}$, which suggested the presence of a characteristic styrylpyrone moiety. The bands at 3444 and $1635 \mathrm{~cm}^{-1}$ in the IR spectrum indicated the presence of a hydroxyl group and conjugated carbonyl moiety, respectively. The ESI-mass measurements in the positive and negative modes revealed its molecular mass to be 448 . The molecular formula of 1 was determined to be $\mathrm{C}_{28} \mathrm{H}_{32} \mathrm{O}_{5}$ by high-resolution EI-mass data (Table 1).

The ${ }^{1} \mathrm{H}$ NMR spectrum of 1 revealed two sets of signals at $\delta 0.91$ and $0.92,0.81$ and $0.82,1.42$ and 1.43, 5.44 and 5.48, and 6.39 and 6.40 in the same ratio of intensity, which suggested that 1 was a mixture of two components, $\mathrm{A} 1$ and $\mathrm{A} 2$, and the mixture could not be separated by HPLC. Thus, a structure analysis of the mixture of A1 and A2 was conducted using NMR. The proton peaks of A1 and A2 in the aromatic region between $\delta 6.77$ and 7.4 perfectly overlapped each other, whereas the methyl groups and $\mathrm{sp}^{2}$ methines between $\delta 4.5$ and 5.5 appeared as two set of signals. First, we attempted to elucidate the structure of one of the components of the A1/A2 mixture. The ${ }^{1} \mathrm{H}$ NMR spectrum revealed signals attributable to three aromatic protons from a 1,2,4-trisubstituted phenyl moiety at $\delta 6.77(\mathrm{~d}, J=8.4 \mathrm{~Hz}), 6.95$ $(\mathrm{dd}, J=1.2,8.4 \mathrm{~Hz})$ and $7.02(\mathrm{~d}, J=1.2 \mathrm{~Hz})$, a methine singlet at $\delta 6.14$, a trans-disubstituted double bond unit at $\delta 6.59(\mathrm{~d}, J=15.9 \mathrm{~Hz})$ and $7.30(\mathrm{~d}, J=15.9 \mathrm{~Hz})$, a cis-disubstituted double bond unit at $\delta 5.44$ $(\mathrm{d}, J=10.5 \mathrm{~Hz})$ and $6.39(\mathrm{~d}, J=10.5 \mathrm{~Hz})$, a terminal methylene protons at $\delta 4.55$ (br, s) and 4.79 (br, s), five methylenes at $\delta 1.50-2.10$ that significantly overlapped each other, and three methyl singlets at $\delta 0.81$, 0.91 and 1.42 (Table 2). In the ${ }^{13} \mathrm{C}$ NMR spectrum, many peaks in the aromatic/olefin region were overlapped between the two components, and thus showed a high intensity relative to the separated peaks. However, several methylenes between $\delta 21$ and 42 appeared as two sets of peaks. The heteronuclear multiple quantum coherence (HMQC) spectrum identified all proton-bearing carbons and the ${ }^{1} \mathrm{H}-{ }^{1} \mathrm{H}$ COSY spectrum revealed three partial structures, as shown in Figure 2. The connectivity of the partial structures was determined with the aid of the heteronuclear multiple bond coherence (HMBC) spectrum, as shown in Figure 2. The styrylpyrone moiety was assigned by the long-range correlations from $\mathrm{H}-8$ to C-4a, C-7, C-8a and C- $1^{\prime \prime}, \mathrm{H}-1^{\prime \prime}$ to C-7, C-8 and C- $3^{\prime \prime}, \mathrm{H}-2^{\prime \prime}$ to $\mathrm{C}-7, \mathrm{C}-4^{\prime \prime}$ and $\mathrm{C}-8^{\prime \prime}, \mathrm{H}-7^{\prime \prime}$ to $\mathrm{C}-3^{\prime \prime}$, $\mathrm{C}-5^{\prime \prime}$ and $\mathrm{C}-6^{\prime \prime}$, and $\mathrm{H}-8^{\prime \prime}$ to $\mathrm{C}-2^{\prime \prime}, \mathrm{C}-4^{\prime \prime}$ and $\mathrm{C}-6^{\prime \prime}$. These proton and carbon chemical shift values were in good agreement with the corresponding proton and carbon chemical shifts of hispidin, a representative styrylpyrone compound. ${ }^{4}$ In combination with ${ }^{1} \mathrm{H}-{ }^{1} \mathrm{H}$ COSY data, the long-range correlations from two methyl singlets at $\mathrm{H}-10^{\prime}$ and $\mathrm{H}-11^{\prime}$ to $\mathrm{C}-3^{\prime}, \mathrm{C}-4^{\prime}$ and $\mathrm{C}-5^{\prime}$ revealed the presence of a 1,1-dimethyl-3-methylene-2-ethylcyclohexane moiety. Long-range correlations of $\mathrm{H}-4$ to $\mathrm{C}-2, \mathrm{C}-5$ and $\mathrm{C}-8 \mathrm{a}$, and $\mathrm{H}-12^{\prime}$ to $\mathrm{C}-2, \mathrm{C}-3$ and $\mathrm{C}-\mathrm{1}^{\prime}$

${ }^{1}$ Division of Biotechnology, College of Environmental and Bioresource Sciences, Chonbuk National University, Iksan, Jeonbuk, Korea and ${ }^{2}$ College of Pharmacy, Chungnam National University, Daejeon, Korea

Correspondence: Professor B-S Yun, Division of Biotechnology, College of Environmental and Bioresource Sciences, Chonbuk National University, Iksan, Jeonbuk 570-752, Korea. 
<smiles>C=C1CCCC(C)(C)C1CCC1(C)C=Cc2c(O)cc(C)cc2O1</smiles>

Figure 1 Structures of phellinins $A 1$ and $A 2$ (1), cyclorenierins $A$ and $B$, and siccanochromene $A$.

Table 1 Physicochemical properties of 1

\begin{tabular}{ll}
\hline Appearance & Orange powder \\
Molecular weight & 448 \\
Molecular formula & $\mathrm{C}_{28} \mathrm{H}_{32} \mathrm{O}_{5}$ \\
ESI mass $(\mathrm{m} / \mathrm{z})$ & \\
$\quad$ In negative mode & $447.6[\mathrm{M}-\mathrm{H}]^{-}$ \\
HR-EI mass $(\mathrm{m} / \mathrm{z})$ & \\
$\quad$ Found & 448.2250 \\
$\quad$ Calcd & 448.2250 \\
UV $\lambda_{\max } n m(\log \varepsilon)$ & $206(4.16)$ \\
& $257(3.82)$ \\
& $391(4.07)$ \\
IR $v_{\max }(\mathrm{KBr}) \mathrm{cm}^{-1}$ & $3444,1635,1458$
\end{tabular}

linked all partial structures. By a process of elimination, C-2 and C-8a were connected by an ethereal linkage, which consequently formed a 2-methylpyran moiety. In addition, $\mathrm{HMBC}$ correlations from $\mathrm{H}-5^{\prime}$ to $\mathrm{C}-4^{\prime}, \mathrm{C}-10^{\prime}$ and $\mathrm{C}-11^{\prime}, \mathrm{H}-9^{\prime}$ to $\mathrm{C}-3^{\prime}$ and $\mathrm{C}-5^{\prime}$, and $\mathrm{H}-2^{\prime}$ to $\mathrm{C}-2$ and $\mathrm{C}-$ $4^{\prime}$ were evident. Therefore, on the basis of its structure, this compound was definitively shown to be a new styrylpyrone compound.

The molecular weight of the other component was the same as the one described above and its ${ }^{1} \mathrm{H}$ and ${ }^{13} \mathrm{C}$ NMR peaks overlapped significantly with the corresponding signals of the above component, suggesting that this component was an isomer. In the ${ }^{1} \mathrm{H}$ NMR spectrum, the signals from the styrylpyrone moiety, such as the three aromatic protons attributed to a 1,2,4-trisubstituted phenyl moiety at $\delta 6.77(\mathrm{~d}, J=8.4 \mathrm{~Hz}), 6.95(\mathrm{dd}, J=1.2,8.4 \mathrm{~Hz})$ and $7.02(\mathrm{~d}, J=1.2 \mathrm{~Hz})$, a methine singlet at $\delta 6.14$ and a trans-disubstituted double bond unit at $\delta 6.59(\mathrm{~d}, J=15.9 \mathrm{~Hz})$ and $7.30(\mathrm{~d}, J=15.9 \mathrm{~Hz})$, were observed, and these signals completely overlapped with the corresponding signals of the other component. However, the signals from the cis-disubstituted double bond at $\delta 5.48(\mathrm{~d}, J=10.5 \mathrm{~Hz})$ and $6.40(\mathrm{~d}, J=10.5 \mathrm{~Hz})$ and three singlet methyls at $\delta 0.82,0.92$ and 1.43 were slightly different
Table $2{ }^{1} \mathrm{H}$ and ${ }^{13} \mathrm{C}$ NMR spectral data for 1 in $\mathrm{CD}_{3} O \mathrm{D}^{\mathrm{a}}$

\begin{tabular}{|c|c|c|}
\hline No. & $\delta_{C}$ & $\delta_{H}$ \\
\hline 2 & $84.6 / 84.5$ & \\
\hline 3 & $126.0 / 125.9$ & $5.48 / 5.44(1 \mathrm{H}, \mathrm{d}, J=10.5)^{\mathrm{b}}$ \\
\hline 4 & $117.43 / 117.40$ & 6.40/6.39 (1H, d, J=10.5) \\
\hline $4 a$ & 99.4 & \\
\hline 5 & 163.9 & \\
\hline 7 & 161.4 & \\
\hline 8 & 101.1 & $6.14(1 \mathrm{H}, \mathrm{s})$ \\
\hline $8 a$ & 166.7 & \\
\hline $1^{\prime}$ & 41.6 & $1.57(1 \mathrm{H}, \mathrm{m}), 1.35(1 \mathrm{H}, \mathrm{m})$ \\
\hline $2^{\prime}$ & 21.5 & $1.60(1 \mathrm{H}, \mathrm{m}), 1.50(1 \mathrm{H}, \mathrm{m})$ \\
\hline $3^{\prime}$ & 55.4 & $1.65(1 \mathrm{H}, \mathrm{m})$ \\
\hline $4^{\prime}$ & $35.9 / 35.8$ & \\
\hline $5^{\prime}$ & 37.2 & $1.45(1 \mathrm{H}, \mathrm{m}), 1.19(1 \mathrm{H}, \mathrm{m})$ \\
\hline $6^{\prime}$ & 24.7 & $1.50(2 \mathrm{H}, \mathrm{m})$ \\
\hline $7^{\prime}$ & 33.4 & $2.02(2 \mathrm{H}, \mathrm{m})$ \\
\hline $8^{\prime}$ & 150.4 & \\
\hline $9^{\prime}$ & 110.0 & $4.79(1 \mathrm{H}, \mathrm{br} \mathrm{s}), 4.55(1 \mathrm{H}, \mathrm{br} \mathrm{s})$ \\
\hline $10^{\prime}$ & 28.8 & $0.92 / 0.91(3 \mathrm{H}, \mathrm{s})$ \\
\hline $11^{\prime}$ & 26.7 & $0.82 / 0.81(3 \mathrm{H}, \mathrm{s})$ \\
\hline $12^{\prime}$ & $27.9 / 27.8$ & $1.43 / 1.42(3 \mathrm{H}, \mathrm{s})$ \\
\hline $1^{\prime \prime}$ & 116.8 & $6.59(1 \mathrm{H}, \mathrm{d}, J=15.9)$ \\
\hline $2^{\prime \prime}$ & 137.4 & $7.30(1 \mathrm{H}, \mathrm{d}, J=15.9)$ \\
\hline $3^{\prime \prime}$ & 128.9 & \\
\hline $4^{\prime \prime}$ & 114.9 & $7.02(1 \mathrm{H}, \mathrm{d}, J=1.2)$ \\
\hline $5^{\prime \prime}$ & 146.8 & \\
\hline $6^{\prime \prime}$ & 148.8 & \\
\hline $7^{\prime \prime}$ & 116.6 & $6.77(1 \mathrm{H}, \mathrm{d}, J=8.4)$ \\
\hline $8^{\prime \prime}$ & 122.1 & $6.95(1 \mathrm{H}, \mathrm{dd}, J=8.4,1.2)$ \\
\hline
\end{tabular}

bProton resonance integral, multiplicity and coupling constant $(J=\mathrm{Hz})$ are in parentheses.

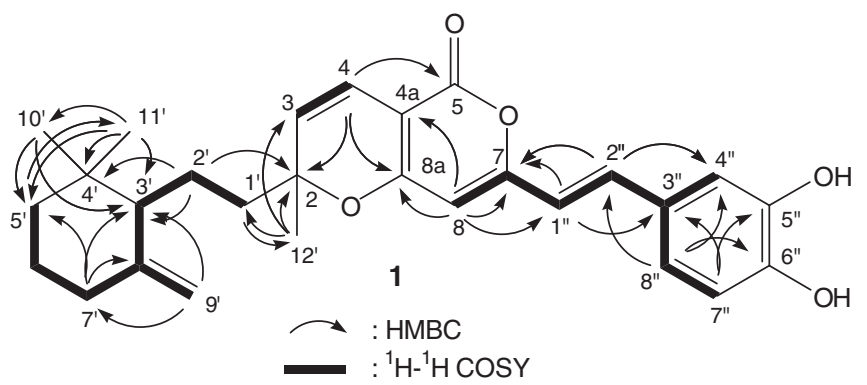

Figure 2 Key correlations in $\mathrm{HMBC}$ and ${ }^{1} \mathrm{H}-{ }^{1} \mathrm{H}$ COSY experiments of compound 1 .

from those of the earlier component in regard to their chemical shifts (Table 2). In the ${ }^{13} \mathrm{C}$ NMR spectrum, all carbon peaks except for C-2, C-3, C-4, C- $4^{\prime}$ and C-12' overlapped with those of the earlier component. The ${ }^{1} \mathrm{H}-{ }^{1} \mathrm{H}$ COSY spectrum revealed that the structure of this component was identical to the one described above, as shown in Figure 2. The long-range correlations from $\mathrm{H}-4$ to $\mathrm{C}-2$ and from $\mathrm{H}-10^{\prime}$ and $\mathrm{H}-11^{\prime}$ to $\mathrm{C}-3^{\prime}, \mathrm{C}-4^{\prime}$ and $\mathrm{C}-5^{\prime}$ confirmed that its planar structure was the same as that of the above structure.

To establish the relative stereochemistry and complete NMR assignments, we measured the NOESY spectrum. However, the significant overlapping of signals and very close corresponding signals of both components prevented us from being able to accurately interpret the NOESY spectrum. Phellinin A is a mixture of stereoisomers and these 
<smiles>C=C1CCCC(C)(C)C1CC/C(C)=C/CO[R6](=O)O[Na]</smiles>

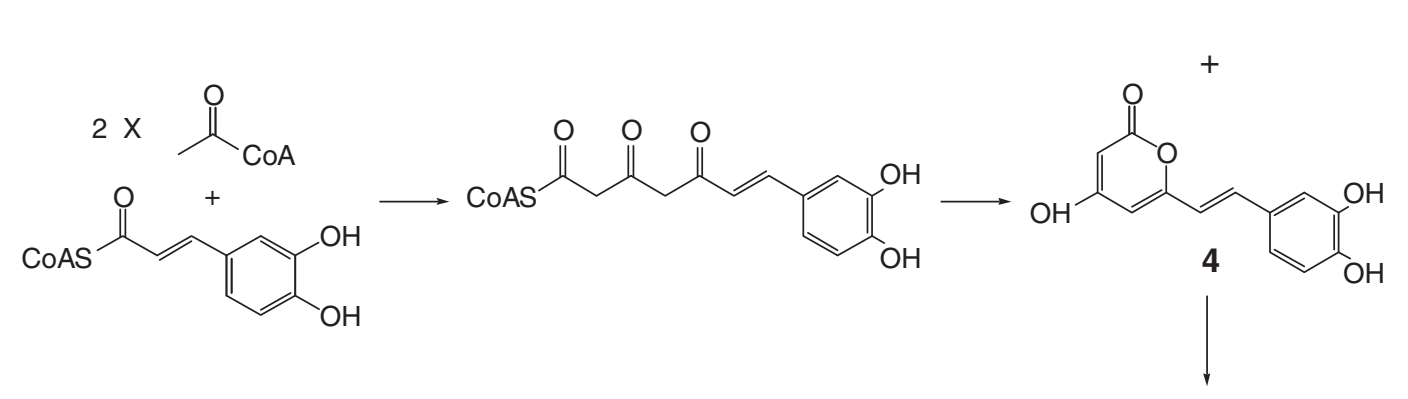<smiles>C=C1CCCC(C)(C)C1CCC1(C)C=CC2C(=O)OC(/C=C/c3ccc(O)c(O)c3)=CC2O1</smiles><smiles>C=C1CCCC(C)(C)C1CC/C(C)=C/CC1C(=O)OC(/C=C/c2ccc(O)c(O)c2)=CC1O</smiles>

Figure 3 Proposed biosynthesis of phellinins A1 and A2 (1).

compounds possess two chiral centers at C-2 and C- $3^{\prime}$. Two sets of ${ }^{1} \mathrm{H}$ and ${ }^{13} \mathrm{C}$ NMR peaks should be derived from the $\alpha$ - and $\beta$-configuration of $\mathrm{C}-2$ relative to $\mathrm{C}-3^{\prime}$. Therefore, we designated phellinin $\mathrm{A} 1$ as the $\alpha$-configuration and phellinin $\mathrm{A} 2$ as the $\beta$-configuration.

Several compounds possessing closely related structures have been identified earlier, including siccanochromene A from the pathogenic fungus $H$. siccans $s^{1}$ and cyclorenierins $\mathrm{A}$ and $\mathrm{B}$ from the sponge Haliclona sp. ${ }^{2}$ Cyclorenierins A and B, sesquiterpenoid quinols, were obtained as a mixture of inseparable $\alpha$ and $\beta$ isomers, respectively. The comparison of phellinin A with siccanochromene A made it possible to propose a biogenetic pathway. ${ }^{5}$ The siccanochromene A was assumed to be a possible intermediate in the biosynthesis of the terpenoid, siccanin. The proposed biosynthesis of siccanochromene A was supported by experiments with both cell-free and intact cell systems of H. siccans Drechsler from farnesyl pyrophosphate (2). ${ }^{6}$ As depicted in Figure 3, the biosynthesis of trans- $\gamma$-monocyclofarnesyl pyrophosphate (3) is believed to proceed stereoselectively by cyclization of trans,trans-farnesyl pyrophosphate (2). Hispidin (4) was shown to be synthesized from phenylalanine through a cinnamyl derivative that was combined with malonate through the polyketide pathway in a cultured fungal strain. ${ }^{7,8}$ The condensation of trans- $\gamma$ monocyclofarnesyl pyrophosphate with hispidin would yield compound $\mathbf{5}$, and the oxidative and nonstereoselective cyclization of $\mathbf{5}$ might form isomers of phellinin A (1). To the best of our knowledge, this is the first case of condensation of hispidin and of an isoprene unit and represents a new group of a natural polyketide-isoprenoid hybrid compound with antioxidant activity.

\section{ACKNOWLEDGEMENTS}

This work was supported by a grant (20080401-034-069) from the BioGreen 21 Program of Rural Development Administration (RDA), Republic of Korea.

1 Nozoe, S. \& Suzuki, K. T. The isolation and structure of siccanochromenes. Tetrahedron 27, 6063-6071 (1971).

2 Jaspars, M., Horton, P. A., Madrid, L. H. \& Crews, P. The cyclorenierins, sesquiterpenoid quinols from the sponge Haliclona sp. collected in Vanuatu. J. Nat. Prod. 58, 609-612 (1995).

3 Lee, I. K., Seo, G. S., Jeon, N. B., Kang, H. W. \& Yun, B. S. Phellinins A1 and A2, new styrylpyrones from the culture broth of Phellinus sp. KACC93057P: I. Fermentation, taxonomy, isolation and biological activities. J. Antibiot. 62, 631-634 (2009).

4 Lee, I. K. \& Yun, B. S. Highly oxygenated and unsaturated metabolites providing a diversity of hispidin class antioxidants in the medicinal mushrooms Inonotus and Phellinus. Bioorg. Med. Chem. 15, 3309-3314 (2007).

5 Trost, B. M., Shen, H. C. \& Surivet, J. P. Biomimetic enantioselective total synthesis of (-)-siccanin via the Pd-catalyzed asymmetric allylic alkylation (AAA) and sequential radical cyclizations. J. Am. Chem. Soc. 126, 12565-12579 (2004).

6 Suzuki, K. T. \& Nozoe, S. Biosynthesis of an antibiotic, siccanin. Bioorganic Chem. 3, 72-80 (1974).

7 Perrin, P. W. \& Towers, G. H. N. Hispidin biosynthesis in cultures of Polyporus hispidus. Phytochemistry 12, 589-592 (1973).

8 Nambudiri, A. M. D., Vance, C. P. \& Towers, G. H. N. Effect of light on enzymes of phenylpropanoid metabolism and hispidin biosynthesis in Polyporus hispidus. Biochem. J. 134, 891-897 (1973). 